\title{
Is intentional publishing in predatory journals a form of scientific misconduct?
}

\author{
C Stein, $\mathrm{PhD}$ \\ Department of Emergency Medical Care, Faculty of Health Sciences, University of Johannesburg, South Africa
}

Corresponding author: C Stein (cstein@uj.ac.za)

\begin{abstract}
Predatory journals are widely acknowledged as a significant problem in scholarly publishing and, more broadly, as a threat to the responsible conduct of research. Because predatory publishers base their operations on deception, it is possible for well-intentioned researchers to unwittingly end up publishing their work in predatory journals. Of a more problematic nature is the behaviour of researchers who intentionally publish in predatory journals as a way of bypassing legitimate peer review. In such cases it is important to decide how such behaviour should be classified, as a way of developing policy aimed at deterrence. The aim of this study was to answer the question as to whether intentional publishing in predatory journals can be considered a form of scientific misconduct, based on the critical application of four conditions taken as being requirements for this. It is not currently possible to satisfy all four conditions that would include intentional publishing in predatory journals as a form of scientific misconduct. However, there are grounds to argue that this behaviour satisfies the definition of a questionable research practice. Regardless of exactly where intentional publishing in predatory journals is placed in the spectrum of unethical research behaviours, there is an urgent need for coherent institutional policy to effectively deal with it and, more broadly, with naive publishing in predatory journals.
\end{abstract}

S Afr J Bioethics Law 2020;13(1):57-61. https://doi.org/10.7196/SAJBL.2020.v13i1.708

The phenomenon of predatory publishing is widely considered to pose a significant threat to the integrity of the scientific enterprise. First coined by Jeffrey Beall in 2010, the term predatory journal refers to publications that require article-processing charges without providing legitimate editorial services. ${ }^{[1,2]}$ Almost a decade later, a formal consensus definition of predatory publishing and predatory journals has been proposed. ${ }^{[3]}$ Predatory journals are motivated singularly by profit without regard for quality, sound editorial and publication practices, scientific rigour or ethical acceptability as part of the peer review and publishing process. Consequently, predatory publishing practices fundamentally undermine the self-correcting nature of science, leading to, among other things, erosion of public trust in science. ${ }^{[4]}$

Because predatory publishers centre their practices on deception, ${ }^{[3-5]}$ it is possible for authors to unwittingly have their work published in predatory journals. The better informed authors are about the practices of predatory publishers, the less likely this is to happen. However, because predatory publishers can be skilled at obscuring their motives, and because publishing practices are seldom guided by well-developed policy that may identify risky journals, well-meaning authors may still unknowingly fall prey to predators.

Although unwitting entrapment by some in the predatory publishing cycle is a problem, an even greater and more worrying problem is the group of authors who choose to publish in predatory journals. The intense pressure on academics to publish in order to secure tenure, attract research funding, be promoted or gain prominence in their disciplines may push some to consider publishing in predatory journals, where the lack of quality peer review assures a high acceptance rate.
This pressure is magnified in South Africa (SA), where the Department of Higher Education and Training subsidises universities for research published by affiliated authors in its accredited journals, some of which have been identified in the past as predatory. ${ }^{[6]}$

Despite the threat that predatory journals pose to scientific integrity and public trust in science, and the significant harm that predatory publishing undoubtedly does, publishing practices in predatory journals by researchers have not traditionally been considered to fall within the ambit of scientific misconduct. Clearly identifying where this behaviour lies in terms of misconduct is important, as it is likely to shape institutional policy, which might play a significant role in both raising awareness of predatory publishing, and in enforcement and deterrence of this behaviour, particularly intentional publishing in predatory journals.

\section{Defining scientific misconduct}

Scientific misconduct is most frequently defined in terms of a wellknown triad - fabrication of data, falsification of data and plagiarism (the so-called 'FFP'). The FFP triad is by far the most widely used definition of scientific misconduct, mainly because it is the definition used by the US federal government in relation to all US research funding agencies. ${ }^{[7-9]}$ Although definitions of scientific misconduct used prior to 2000 by the US public health service included FFP plus a broad 'serious deviations from accepted practices' clause, this clause was dropped from 2000 in favour of the revised definition, which limits scientific misconduct to only FFP. ${ }^{[8]}$

While this US definition of scientific misconduct must be applied by institutions in the USA in order to access research funding, institutions are not prohibited from extending the FFP definition for use within 
their own research domains. In an extensive survey of universities in the USA, Resnik et al. ${ }^{[8]}$ identified several other behaviours used to define scientific misconduct, including unethical authorship practices (other than plagiarism), misuse of confidential information, violation of other regulations, misappropriation of property or funds, failure to disclose conflicts of interest and 'other serious deviations', among others. While seemingly a more encompassing definition than FFP alone, there appears to be a wide degree of variation in the application of these behaviours to misconduct definitions, and some of them, such as violation of other regulations and 'other serious deviations', seem to be unhelpfully vague.

\section{Intentional publishing in predatory journals as scientific misconduct}

More recently, in an attempt to address the limited existing definitions of scientific misconduct, Resnik ${ }^{[10]}$ has proposed a set of four conditions for the inclusion of a behaviour as a form of scientific misconduct. These four conditions have been chosen mainly because they speak to legally enforceable standards for the ethical conduct of research. Resnik's four criteria will be used below as a way of interrogating whether there are grounds to conclude that publishing in predatory journals can be considered a form of scientific misconduct. Only intentional publishing in predatory journals, in other words publishing in predatory journals by authors who are fully aware that they are doing so, will be considered in relation to the four conditions below. This is not to say that unintentional or naive predatory publishing is harmless - it is not. However, as with other types of behaviour considered to fit the definition of scientific misconduct (FFP, for example), intent is an important component, and 'honest mistakes' are not considered to imply misconduct. ${ }^{\text {[10 }}$

\section{Condition 1: The behaviour is widely regarded as highly unethical}

In describing this condition, Resnik ${ }^{[10]}$ refers to a normative scale of research behaviour, with responsible conduct of research on one end and misconduct on the other. Existing behaviours such as FFP are placed within the category of 'highly' unethical at this one extreme. However, there is no objective way of evaluating what makes a behaviour 'highly' unethical, as opposed to merely unethical, other than perhaps the role played by the researcher's mental state. What makes FFP so morally repugnant is that these behaviours are wilful and not merely a mistake or a lapse in what would otherwise be appropriate skill and care.

Publishing in predatory journals can be described as unethical behaviour for a number of reasons. In essence, by doing this, authors fail to reject, and in fact buy into, the unethical practices of those behind the many predatory publication platforms - practices that are centred on deception and reckless disregard for quality in research and critically important public trust in science. Perhaps more importantly, researchers who make publishing in predatory journals part of their own strategy, and pass off these publications as legitimate, engage in their own form of academic deception in doing so. They cheat the system that others engage in honestly, for selfish reasons. Every article-processing charge paid to a predatory publisher further supports and advances their cause, sustaining their unethical practices and making it more likely that other researchers will be caught in the predatory net. Thus choosing predatory journals is not only a single unethical choice, it has broader implications for the propagation of a pervasive threat to the responsible conduct of research.

\section{Condition 2: The behaviour significantly threatens the integrity of science}

In order to threaten the integrity of science, a behaviour should be contrary or damaging to the goals of science, that is, knowledge generation that is a reflection of the true state of the natural world. ${ }^{[10]}$ It is in this area, perhaps, that publishing in predatory journals has its most clear-cut association with misconduct, due to the tremendous potential that it has to damage the scientific project.

The generation of new scientific knowledge serves a number of interests, but in the broadest sense, it is first and foremost in the public good. Scientific discoveries bring better quality of life for many, make the world safer, alleviate suffering and promote a better social order, among many other goods. Predatory publishing practices directly undermine the integrity of scientific knowledge production by placing research in the public domain without the quality control of proper peer review, and doing so in an intentionally deceptive manner.

Public trust in science is founded squarely on its self-correcting nature and rigorous quality control. Predatory publishing not only disables the peer review process, thus weakening quality control, but through its deception and misrepresentation it also creates a great deal of uncertainty in both professional and public spaces about what exactly is legitimate science and what is not. This inevitably leads to a breakdown of public trust in science. Both members of the public and professionals are left wondering who and what to trust.

As a measure of its threat to scientific integrity, is it possible to equate publishing in predatory journals to FFP on this count? Fabrication and falsification may introduce flawed data and invalid results into the public domain, and are thus considered to constitute a significant threat to scientific integrity. Plagiarism, interestingly, does not - if plagiarism is the only form of misconduct, then the validity of results stands - however, it does erode the social structure of science, and trust among researchers, as put forward by Resnik. ${ }^{[10]}$ Considering the above description of predatory publishing's effects on scientific integrity, it appears to be as harmful as either falsification or fabrication, and perhaps even more so than plagiarism.

\section{Condition 3: The behaviour can be clearly defined}

The importance of clarity in defining a behaviour that is classified as misconduct lies in avoidance, deterrence and enforcement. ${ }^{[10]}$ Behaviours that are vaguely defined may be difficult, or even impossible, to avoid by researchers. Equally, clarity is important for enforcement, and ultimately for deterrence - researchers would undoubtedly view it as unfair to be held accountable for behaviours so poorly defined that they find it difficult to avoid them. A clear definition of intentional publishing in predatory journals depends on defining two parts: (i) defining what constitutes a predatory journal; and (ii) defining what constitutes intent to publish in one. Both of these may be problematic, and subject to significant differences in opinion.

There still exists no way of identifying predatory journals (or publishers) with any quantifiable degree of validity or reliability. The most frequently cited authority for identifying predatory journals seems to be Beall's ${ }^{[2]}$ list, which was taken offline by Beall himself in 
2017, but is still available and is being maintained anonymously. ${ }^{[11]}$ While Beall's criteria for identifying publishers and journals as predatory are available, ${ }^{[12]}$ it is not known exactly how these were applied, and to what extent this list was exhaustive, or whether other information played a role. Beall certainly seems to have considered factors other than those in his stated list of criteria when classifying journals or publishers as predatory, as his addition of the Frontiers group of journals to Beall's list indicates. ${ }^{[13]}$ While many trust Beall's intuition in reality, little is known in detail about the criteria that were used by him to classify journals as predatory, and how this was done. Some have criticised this as a weakness of the list and Beall's modus operandi. ${ }^{[14]}$ Without any way of rigorously defending how Beall's list comes to contain the journals (and publishers) that it does, using it as a way of defining predatory journals would not stand up to the most basic scrutiny.

Although Beall enjoys some prominence by way of his original blacklist, other approaches exist as methods to identify predatory journals and publishers. Other blacklists exist, for example, Cabell's list, along with whitelists such as the Directory of Open Access Journals, and Cabell's whitelist. ${ }^{[15,16]}$ All of these lists are, to some degree, inconsistent, and may even contain contradictory entries, offering authors little in the way of reliable guidance in journal choice. ${ }^{[15]}$ Many authors have assembled their own checklists to guide their peers and colleagues in avoiding predatory journals. Unfortunately there are far too many checklists in existence, and far too few with meaningful scientific methods behind their development, to offer much real guidance. ${ }^{[3]}$ As a result of the current difficulty in identifying predatory journals, those claiming that a researcher has published in a predatory journal and that this deserves sanction may find it difficult to reject a defence that highlights this problem.

Assuming that it may be possible to reliably identify predatory journals, how would intentionality to publish in one be defined? This could only be determined by ruling out accidental or naive choice of a predatory journal, which in turn requires a detailed history of publication and, in the event of previous such instances, an intervention. In other words, intentional publishing in a predatory journal could only be defined within the context of a policy that provides a framework for surveillance and discovery, along with steps to be taken the first time a researcher unknowingly publishes in a predatory journal. The absence of such a policy would make it very difficult, if not impossible, to show that what is thought to be intentional could in fact be a string of 'honest mistakes'.

\section{Condition 4: Existing methods of enforcement or deterrence are inadequate}

In considering whether existing methods of enforcement or deterrence may preclude the necessity of labelling intentional predatory publishing as scientific misconduct, we should reflect on what those methods might be in the SA higher education environment at present. Currently, the only thing possibly fitting this description is institutional policy as a means of deterring authors from intentionally selecting predatory journals to publish their work. It is unknown to what extent SA higher education institutions or funding bodies actually have such policies, and if they do, what kind of deterrence they may offer.

Statements about the existence and dangers of predatory journals, and in some cases institutional positions, are published or promoted sporadically in SA. For example, De Jager et al., ${ }^{[17]}$ in their survey of predatory publishing prevalence in economic and management sciences, cite statements by the National Research Foundation, the Department of Higher Education and Training and two universities regarding awareness of predatory journals. The National Research Foundation statement on predatory journals and deceptive publishers cites rejection of applications associated with such practices as one form of deterrence, and encourages institutions to be aware of and avoid publishing in predatory journals. ${ }^{[18]}$

Likewise, the Department of Higher Education and Training, in its report on 2017 university research outputs, mentions the problem of predatory journals, and the position that it takes on research output subsidy claims for publications in such journals. ${ }^{[19]}$ This position involves the withholding or withdrawal of the research subsidy where research is published in predatory journals, and is no doubt intended as a deterrent. However, it is very difficult at present, if not impossible, to enforce such a position, or to rule fairly. The department found this out in $\mathbf{2 0 1 6}$ when it withdrew the research subsidy for all research published in a list of predatory and 'possibly' predatory journals - and had to overturn its decision and reinstate these allocations after an outcry based on the validity of the lists.

Most recently, a joint statement by six SA governmental and non-governmental research and scientific publishing stakeholders on scholarly publishing practices has made specific reference to publishing in predatory journals. ${ }^{[20]}$ The statement places the onus for avoidance of predatory journals on individual researchers, but also places some responsibility on higher education institutions to put in place 'processes of scrutiny' that will presumably bring about some measure of both awareness and deterrence. What these processes might entail is currently not clear.

It seems that in SA at present there is, at most, awareness of the predatory publishing risk among higher education institutions and bodies such as the National Research Foundation and Department of Higher Education and Training. However, there appears to be a lack of coherence and co-ordination regarding a response to this problem, and no meaningful policy on it, to the extent that there is not even a uniformly agreed upon way of identifying predatory journals. This remains the case despite continued threats by the department to not subsidise research published in such journals. In this setting, it is difficult to conclude that methods of deterrence (such as withholding the publication subsidy) are inadequate, because the demonstration of inadequacy presupposes an existent policy, implementation and procedural framework.

\section{Summary}

From the above arguments, it is doubtful that intentional publishing in predatory journals can be considered to adequately satisfy all four of Resnik's ${ }^{[10]}$ conditions for defining a behaviour as scientific misconduct. The case for conditions 1 and 2 is strong; however, the case for condition 3 is currently weak because it is not possible to accurately and precisely identify predatory journals. While some are dead giveaways, others are much more deceptive, and may be difficult to judge as predatory with any degree of certainty. The case for condition 4 is uncertain owing to a dearth of existing predatory publishing policy, which is a prerequisite for judgements about the adequacy of enforcement or deterrence measures. 


\section{If not scientific misconduct, then what?}

If, as argued above, intentional publishing in predatory journals cannot be considered a form of scientific misconduct, then how should it be defined in order to convey its ethically problematic nature? The normative scale of research behaviour referred to above, ranging from the opposite extremes of responsible conduct of research to scientific misconduct, has as its middle ground the notion of questionable research practices (QRPs).

QRPs are defined as 'actions that violate traditional values of the research enterprise and that may be detrimental to the research process', and are differentiated from scientific misconduct mainly on the basis that they are considered to not directly harm the integrity of the research process. ${ }^{[21]}$ Rather, they are considered to 'erode confidence' in research integrity. There is little consensus on many aspects of the above definition, and sometimes the distinction between QRPs and scientific misconduct is difficult to make, depending only on details related to scope or context of an action. ${ }^{[22]}$ Although QRPs are thought to be less serious than scientific misconduct, their potential for harming research integrity is arguably greater than is often appreciated, both because of their greater prevalence and because of widespread ignorance of and indifference towards their existence. ${ }^{[23]}$ Turning a blind eye to, or tolerating, QRPs can create fertile ground for the growth of scientific misconduct. ${ }^{[21]}$

Can intentionally publishing in predatory journals be considered a QRP? In order to answer this question, it is necessary to consider the above definition of a QRP, and determine whether such a behaviour: (i) violates traditional research values; and (ii) if so, whether this stops short of harming the integrity of the research process and is more in line with the 'erosion of confidence' standard suggested by the US Institute of Medicine definition. ${ }^{[2]}$ The first part of this question appears to be quite straightforward - dishonestly choosing to publish research results in a manner that undermines research integrity and public trust in science cannot be seen as anything other than a violation of traditional research values such as honesty, accountability and integrity at all stages of the research process. The second part of this question, relating to erosion of confidence in research integrity, also seems to be obvious - the effect that this behaviour has on public trust in science provides a strong argument to this effect.

\section{Conclusion}

There is no doubt that the existence of predatory journals and their deceptive practices has real potential to undermine scientific integrity and to weaken the ethical and responsible conduct of research. This is true even if researchers do so unknowingly, but the effect is magnified when this behaviour is intentional, constituting dishonest research practice and wastage of public funding for research in the form of government subsidy. In attempting to respond to the threat of predatory journals at an institutional level, it is useful to consider what existing category of behaviour intentional publishing in predatory journals fits into, as this will, to a large extent, determine how such a response could be implemented within existing policy.

Of the two existing broad categories of behaviour considered to be at odds with responsible conduct of research, a case can only be made currently that intentional publishing in predatory journals can be considered to be a QRP. Although it might be argued that the impact of this behaviour on research integrity could be more serious than that usually associated with a QRP, it is not possible to present a strong argument that it should be classified as misconduct. This is not necessarily because of lessened impact, but is more a result of the uncertainty that exists in identifying predatory journals and the intent of researchers to publish in them.

It is clear from the discussion above that current definitions of scientific misconduct and QRPs are inadequate. This is not a new observation; $;^{[9,10,24]}$ however, it is brought into sharp focus again by attempts to fit a relatively new and rapidly evolving behaviour into one of these old and narrow (misconduct) or vague (QRP) definitions. Both of these definitions are most widely attributed to sources from the USA, where factors related to federal research oversight, either through agencies conducting or funding research, have influenced both the definitions themselves and how they are interpreted. The very narrow definition of scientific misconduct as FFP seems to be based mainly on what can be defended legally by US federal agencies. Globally, many other definitions of scientific misconduct exist, and many of these are broader than FFP. References to publishing in predatory journals are non-existent in such definitions, although the European Code of Conduct for Research Integrity ${ }^{[25]}$ does refer to 'supporting' predatory journals as an unacceptable practice (falling just short of misconduct, which is still the domain of FFP). It is time to move away from definitions of misconduct and QRPs used exclusively in the USA, and to redefine both of these with local relevance, broader scope and practical meaning.

Similarly, clearly defined institutional policy is needed to deal with the problem of publishing in predatory journals, both naively and intentionally. Effectively dealing with this problem will require institutional commitment beyond well-intentioned statements about being 'on the lookout' for and having awareness of predatory journals. ${ }^{[18,19]}$ Well-structured and consistently applied policy is required to define, monitor and discover instances of publishing in predatory journals and to deal with these in a way that emphasises future avoidance, but that also allows suitable sanction for repeated instances of such intentional publishing practice.

\section{Acknowledgements. None. \\ Author contributions. Sole author. Funding. None. \\ Conflicts of interest. None.}

1. Beall J. Predatory publishers are corrupting open access. Nature 2012;489:179. https://doi.org/10.1038/489179a

2. Beall J. What I learned from predatory publishers. Biochem Med 2017;27(2):273281. https://doi.org/10.11613/BM.2017.029

3. Grudniewicz A, Moher D, Cobey KD. Predatory journals: No definition, no defence. Nature 2019;576(7786):210-212. https://doi.org/10.1038/d41586-01903759-y

4. Laine $C$, Winker MA. Ethical issues in publishing in predatory journals. Biochem Medica 2017;2014(2):285-291. https://doi.org/10.11613/bm.2017.031201

5. Petrisor Al. Evolving strategies of the predatory journals. Malaysian J Libr Inf Sci 2016;21(1):1-17. https://doi.org/10.22452/mjlis.vol21 no1.1

6. Mouton J, Valentine A. The extent of South African authored articles in predatory journals. S Afr J Sci 2017;113(7-8):1-9. https://doi.org/10.17159/ sajs.2017/20170010

7. Resnik DB, Rasmussen LM, Kissling GE. An international study of research misconduct policies. Account Res 2015;22(5):249-266. http://doi.org/10.1080/0 8989621.2014.958218

8. Resnik DB, Neal T, Raymond A, Kissling GE. Research misconduct definitions adopted by US research institutions. Account Res 2015;22(1):14-21. http://doi. org/10.1080/08989621.2014.891943 
9. Rossouw TM, Van Zyl C, Pope A. Responsible conduct of research: Global trends, local opportunities. S Afr J Sci 2014;110(1-2):1-6. https://doi.org/10.1590/ sajs.2014/20130103

10. Resnik DB. Is it time to revise the definition of research misconduct? Account Res 2019;26(2):123-137. https://doi.org/10.1080/08989621.2019.1570156

11. Anonymous. Beall's list of predatory journals and publishers. https://beallslist. weebly.com (accessed 5 October 2019).

12. Beall J. Criteria for determining predatory open-access publishers. 2015. https:// beallslist.weebly.com/uploads/3/0/9/5/30958339/criteria-2015.pdf (accessed 5 October 2019).

13. Bloudoff-Indelicato M. Backlash after Frontiers journals added to list of questionable publishers. Nature 2015;526(7575):613. https://doi. org/10.1038/526613f

14. Swauger S. Open access, power, and privilege: A response to 'What I learned from predatory publishing.' Coll Res Libr News 2017;78(11):603-606. https://doi. org/10.25261/ir00000076

15. Strinzel M, Severin A, Milzow K, Egger M. Blacklists and whitelists to tackle predatory publishing: A cross-sectional comparison and thematic analysis. MBio 2019;10(3):1-16. https://doi.org/10.7287/peerj.preprints.27532v1

16. Teixeira da Silva JA, Tsigaris P. What value do journal whitelists and blacklists have in academia? J Acad Librariansh 2018;44(6):781-792. https://doi.org/10.1016/j. acalib.2018.09.017

17. De Jager $P$, de Kock F, van der Spuy P. Do not feed the predators. South African J Bus Management 2017;48(3):35-45. https://doi.org/10.2139/ ssrn. 2858750
18. National Research Foundation. NRF Statement on Predatory Journals \& Deceptive Publishers. Johannesburg: NRF, 2107. https://www.nrf.ac.za/document/04-nrfstatement-predatory-journals-deceptive-publishers (accessed 18 December 2019).

19. Department of Higher Education and Training. Report on the Evaluation of the 2017 Universities' Research Output. Pretoria: DoHET, 2019.

20. Anonymous. Statement on ethical research and scholarly publishing practices. S Afr J Sci 2019;115(11/12):16. https://doi.org/10.17159/sajs.2019/a0316

21. Institute of Medicine. Responsible Science: Ensuring the Integrity of the Research Process: Volume I. Washington, DC: The National Academies Press, 1992.

22. Shamoo AE, Resnik DB. Responsible conduct of research. 3rd ed. New York: Oxford University Press, 2015.

23. Steneck NH. Fostering integrity in research: Definitions, current knowledge, and future directions. Sci Eng Ethics 2006;12(1):53-74. https://doi.org/10.1007/ pl00022268

24. Resnik DB. From Baltimore to Bell Labs: Reflections on two decades of debate about scientific misconduct. Account Res 2003;10(2):123-135. http://doi. org/10.1080/08989620300508

25. All European Academies. The European Code of Conduct for Research Integrity. Revised edition. ALLEA: Berlin, 2017.

Accepted 5 May 2020 